\title{
Invasive treatment for carotid fibromuscular dysplasia
}

\author{
Łukasz M. Tekieli ${ }^{1}$, Damian R. Maciejewski ${ }^{1}$, Karolina Dzierwa ${ }^{1}$, Anna Kabłak-Ziembicka ${ }^{1}$, \\ Michał Michalski², Magdalena Wójcik-Pędziwiatr², Andrzej Brzychczy³, Zbigniew Moczulski ${ }^{4}$, \\ Krzysztof Żmudka1, Piotr Pieniążek ${ }^{1,5}$
}

\begin{abstract}
${ }^{1}$ Department of Interventional Cardiology, Institute of Cardiology, Jagiellonian University Medical College, John Paul II Hospital, Krakow, Poland

${ }^{2}$ Department of Neurology with Stroke Division, John Paul II Hospital, Krakow, Poland

${ }^{3}$ Department of Vascular Surgery and Endovascular Interventions, John Paul II Hospital, Krakow, Poland

${ }^{4}$ Centre for Diagnosis, Prevention and Telemedicine, John Paul II Hospital, Krakow, Poland

${ }^{5}$ Department of Cardiac and Vascular Diseases, Institute of Cardiology, Jagiellonian University Medical College, John Paul II Hospital, Krakow, Poland
\end{abstract}

\begin{abstract}
Introduction: Fibromuscular dysplasia (FMD) is an infrequent non-inflamatory disease of unknown etiology that affects mainly medium-size arteries. The prevalence of FMD among patients scheduled for endovascular treatment of carotid artery stenosis is unknown.

Aim: To evaluate the prevalence and treatment options of carotid FMD in patients scheduled for carotid artery stenting (CAS).

Material and methods: Between Jan 2001 and Dec 2013, 2012 CAS procedures were performed in 1809 patients (66.1\% men; age $65.3 \pm 8.4$ years, $49.2 \%$ symptomatic). In case of FMD suspicion in Doppler-duplex ultrasound (DUS), computed tomography angiography was performed for aortic arch and extracranial and intracranial artery imaging. For invasive treatment of FMD carotid stenosis, balloon angioplasty was considered first. If the result of balloon angioplasty was not satisfactory (>30\% residual stenosis, dissection), stent placement was scheduled. All patients underwent follow-up DUS and neurological examination 3, 6 and 12 months after angioplasty, then annually.

Results: There were 7 (0.4\%) (4 symptomatic) cases of FMD. The FMD group was younger ( $47.9 \pm 7.5$ years vs. $67.2 \pm 8.9$ years, $p=0.0001)$, with higher prevalence of women $(71.4 \%$ vs. $32.7 \%, p=0.0422)$, a higher rate of dissected lesions $(57.1 \%$ vs. $4.6 \%$, $p=0.0002)$ and less severe stenosis $(73.4 \%$ vs. $83.9 \%, p=0.0070)$ as compared to the non-FMD group. In the non-FMD group the prevalence of coronary artery disease was higher (65.1\% vs. $14.3 \%$ in FMD group, $p=0.009)$. All FMD patients underwent successful carotid artery angioplasty with the use of neuroprotection devices. In 4 cases angioplasty was supported by stent implantation.

Conclusions: Fibromuscular dysplasia is rare among patients referred for CAS. In case of significant FMD carotid stenosis, it may be treated with balloon angioplasty (stent supported if necessary) with optimal immediate and long-term results.
\end{abstract}

Key words: carotid fibromuscular dysplasia, carotid artery stenting, stroke.

\section{Introduction}

Fibromuscular dysplasia (FMD) is an infrequent non-inflammatory disease of unknown etiology that affects mainly medium-size arteries. It usually occurs in young women of childbearing age, and in most cases renal and carotid arteries are involved. In a large autopsy study, FMD was found in $0.02 \%$ of $>20000$ consecutively examined carotid arteries [1]. Although carotid FMD is considered by some to be a benign condition, in fact, it may lead to serious complications including transient ischemic attack/stroke (19.2\%), spontaneous dissection (19.7\%) and aneurysm (17\%) [2]. Usually FMD lesions can be appreciated in the middle and distal segments of the extracervical internal carotid artery, not rarely extending to the base of the skull. A typical finding on angiography is multifocal concentric luminal narrowing alternating with areas of mural dilatation that are wider than the original lumen (the string-of-beads appearance) [3, 4]. This finding is present in 80-90\% of patients with FMD. Histopathologic findings are ac-

\section{Corresponding author:}

Łukasz M. Tekieli MD, Department of Interventional Cardiology, Institute of Cardiology, Jagiellonian University Medical College, John Paul II Hospital, 80 Prądnicka St, 31-202 Krakow, Poland, phone: +48 607414 446, e-mail: Itekieli@szpitaljp2.krakow.pl

Received: 14.01.2015, accepted: 22.03.2015. 
cumulations of dysplastic muscle cells forming "fibromuscular hillocks" and disruption of the internal elastic membrane [4]. Macroscopically it leads to microaneurysms and formation of stenotic sections. The prevalence of FMD among patients scheduled for endovascular treatment of carotid artery stenosis is unknown. With the different etiology and lesion morphology FMD may require different treatment strategies as compared to atherosclerotic carotid stenosis.

\section{Aim}

The aim of the present study was to evaluate the prevalence and treatment options of carotid FMD in a population of patients scheduled for carotid artery stenting.

\section{Material and methods}

Between Jan 2001 and Dec 2013, 2012 carotid artery stenting procedures were performed in 1809 patients $[5,6]$. Doppler-duplex ultrasound (DUS) examination and subsequent catheter angiography were procedures qualifying for invasive treatment. The FMD DUS criteria were: segmental string-of-beads pattern with alternating regions of lumen narrowing and vessel dilatation (morphological criteria); location in the distal extracranial part of the internal carotid artery (ICA); direct and/or indirect criteria of stenosis (hemodynamics criterion (optional)) [7]. In case of FMD suspicion computed tomography angiography (CTA) was performed for imaging of the aortic arch and extracranial and intracranial arteries. For atherosclerotic carotid lesions, corresponding guidelines were applied for the revascularization strategy. When FMD stenosis was confirmed in angiography, the indications for revascularization were considered individually. Balloon angioplasty, recommended for symptomatic FMD, was the first line treatment [8]. If the result of balloon angioplasty was not satisfactory (> 30\% residual stenosis, dissection), stent placement was scheduled. All patients underwent follow-up DUS and neurological examination 3, 6 and 12 months after angioplasty, then annually.

\section{Statistical analysis}

Patient demographic, clinical, imaging, and procedural data were entered into a database. Univariate analysis for between-group comparison was performed. A twotailed $t$ test was used for continuous data, and Fisher's exact test was used for categorical data. A $p$ value $<0.05$ was considered to indicate a statistically significant difference (Statistica 8.0, StatSoft Inc).

\section{Results}

Carotid FMD was found in 7 (0.4\%) among 1809 patients who underwent carotid artery stenting. Patients' characteristics of the FMD group and non-FMD group and the comparison between the groups are shown in Table I. As expected, the FMD group was younger, with higher prevalence of woman. There was also a higher rate of dissected lesions and a slightly lower percentage of stenosis in the FMD group as compared to the non-FMD group. As the non-FMD group consisted of $>99 \%$ atherosclerosis-origin lesions, it was not surprising that in this group the prevalence of coronary artery disease was much higher. All 7 patients with FMD underwent carotid artery angioplasty with the use of neuroprotection devices. In 4 cases angioplasty was supported by stent implantation. We present here the three most interesting cases.

Patient 1: A 45-year-old woman with hyperlipidemia presented with a 9-day history of left-hemisphere ischemic stroke accompanied by right-side hemiparesis and motor aphasia. Admission Doppler ultrasound revealed left ICA dissection resulting in near-to-occlusion steno-

Table I. Patients' characteristics $(n=1809)$

\begin{tabular}{|c|c|c|c|}
\hline Characteristics & $\begin{array}{c}\text { FMD group } \\
n=7\end{array}$ & $\begin{array}{c}\text { Non-FMD group } \\
n=1802\end{array}$ & Value of $p$ \\
\hline Age, mean \pm range [years] & $47.9 \pm 7.5(45-63)$ & $67.2 \pm 8.9(36-88)$ & 0.0001 \\
\hline Female, $n(\%)$ & $5(71.4)$ & $589(32.7)$ & 0.0422 \\
\hline Prior neurological symptoms*, $n(\%)$ & $4(57.1)$ & $894(49.6)$ & 0.7242 \\
\hline Arterial hypertension, $n(\%)$ & 7 (100) & $1648(91.5)$ & 1.000 \\
\hline Hyperlipidemia, $n$ (\%) & $5(71.4)$ & $1338(74.3)$ & 1.000 \\
\hline Smoking (current, h/o), $n$ (\%) & $4(57.1)$ & $820(45.5)$ & 0.7087 \\
\hline Diabetes, $n(\%)$ & $1(14.3)$ & $514(28.5)$ & 0.6806 \\
\hline Coronary artery disease, $n(\%)$ & $1(14.3)$ & $1174(65.1)$ & 0.009 \\
\hline History of myocardial infarction, $n(\%)$ & $1(14.3)$ & $475(26.4)$ & 0.6835 \\
\hline Contralateral ICA involved, $n(\%)$ & $1(14.3)$ & $593(32.9)$ & 0.4375 \\
\hline$\%$ stenosis (SD) & $73.4 \pm 18.6$ & $83.9 \pm 2.75$ & 0.0070 \\
\hline Local dissection, $n(\%)$ & $4(57.1)$ & $83(4.6)$ & 0.0002 \\
\hline
\end{tabular}

*Within 6 months prior to CAS. 

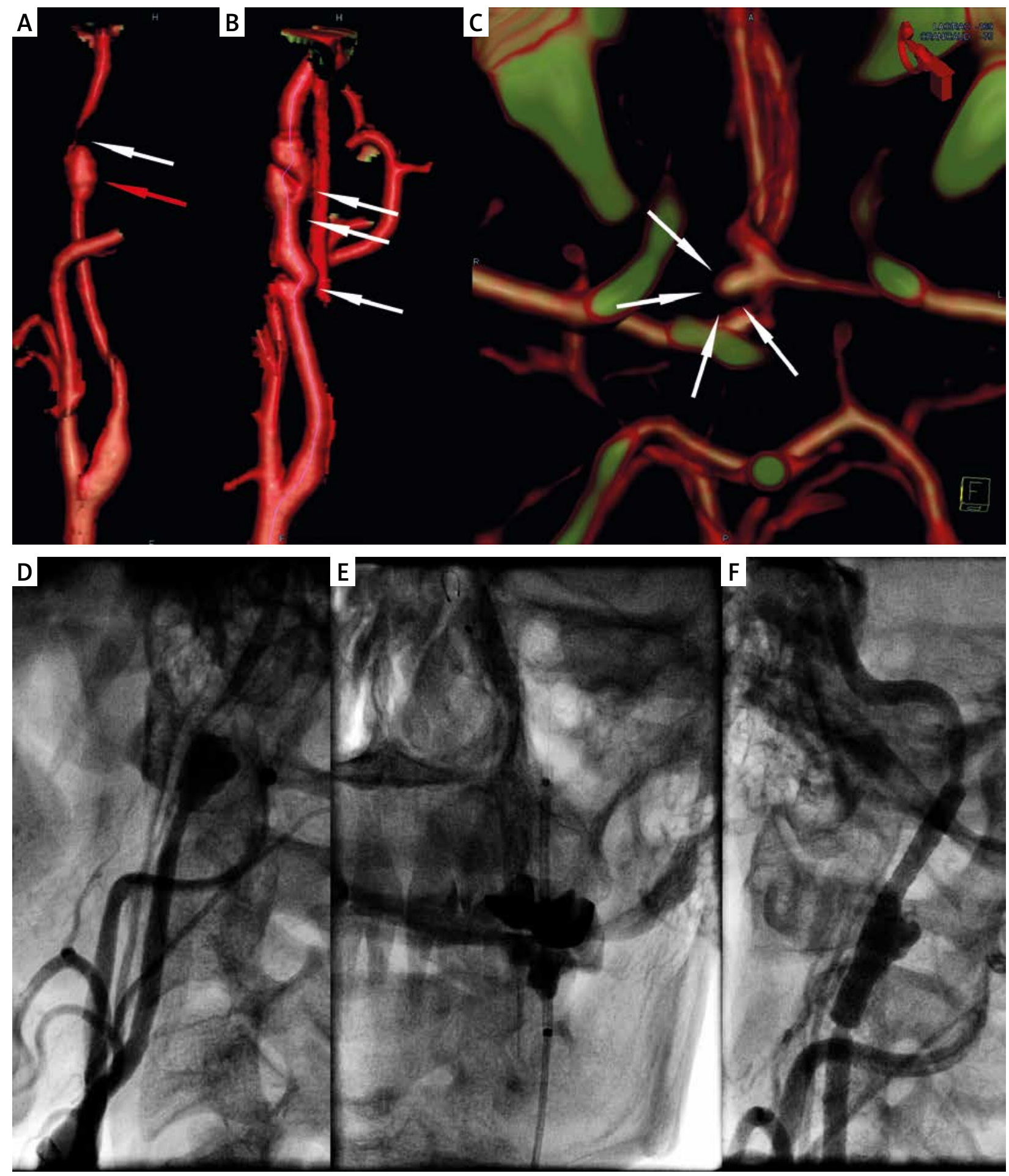

Figure 1. A 45-year-old woman with hyperlipidemia presented with a 9-day history of left-hemisphere ischemic stroke accompanied by right-side hemiparesis and motor aphasia with LICA critical stenosis. A, B, C - CT angiography. A - Spherical left ICA aneurysm $(9 \times 8 \mathrm{~mm})$ with short artery dissection causing near-to-occlusion stenosis at the distal top of the aneurysm at C1 level. B - Right ICA irregular lumen stenosis with 'string-of-beads' morphology typical for fibromuscular dysplasia. C - Small $(3.6 \times 2.8 \mathrm{~mm})$ aneurysm of anterior communicating cerebral artery. D, E, F - catheter angiography. D - subtotal LICA stenosis confirmed by angiography. E - Precise $6 \times 30 \mathrm{~mm}$ self-expanding open-cell stent positioning. $\mathrm{F}$ - optimal angiographic result of LICA-CAS 
sis with low peak systolic $(0.4 \mathrm{~m} / \mathrm{s})$ and end diastolic $(0.25 \mathrm{~m} / \mathrm{s})$ velocities, a delay in systolic acceleration and markedly narrowed artery lumen distally to the stenosis site. Subsequent CTA revealed spherical left ICA (LICA) aneurysm $(9 \times 8 \mathrm{~mm})$ with short artery dissection causing near-to-occlusion stenosis at the distal top of the aneurysm at C1 level (Figure 1 A). Right ICA (RICA) had irregular lumen stenosis with 'string-of-beads' morphology typical for FMD (Figure $1 \mathrm{~B}$ ). Intracranial CTA showed a small $(3.6 \times 2.8 \mathrm{~mm})$ aneurysm of the anterior communicating cerebral artery (Figure $1 \mathrm{C}$ ). After neurological consultation, the patient was referred for urgent carotid artery angioplasty. The left side carotid angiography is shown in Figure $1 \mathrm{D}$. Directly after angiography LICA distal neuroprotected (Spider FX, ev3 Inc., Plymouth, MN, USA) angioplasty was performed with a $4.0 \times 20 \mathrm{~mm}$ balloon. Suboptimal, $40 \%$ residual stenosis was treated with a self-expanding open-cell stent (Precise $6 \times 30 \mathrm{~mm}$, Cordis, a Johnson \& Johnson company, Miami Lakes, FL, USA) (Figure $1 \mathrm{E}$ ). No postdilatation was required, and the final result was optimal (Figure $1 \mathrm{~F}$ ). The periprocedural and postprocedural period was uneventful. For the next 42 months of follow-up she has not demonstrated any new neurological symptoms and DUS evaluation has not indicated in-stent restenosis or significant right ICA stenosis progression.

Patient 2: A 63-year-old female patient with hypertension and a history of ST elevation anterior myocardial infarction (MI) presented with asymptomatic bilateral carotid bruit and CCS 3 angina for further non-invasive and invasive evaluation. Admission DUS showed bilateral ICA stenosis with peak systolic velocity/end diastolic velocity (PSV/EDV) of $1.5 / 0.6 \mathrm{~m} / \mathrm{s}$ on the left side and PSV/EDV of $3.1 / 1.3 \mathrm{~m} / \mathrm{s}$ on the right side (> $80 \%$ stenosis according to the Bluth criteria). Interestingly, 6 months earlier RICA PSV/EDV were $1.9 / 0.9 \mathrm{~m} / \mathrm{s}$. Figures $2 \mathrm{~A}$ and B show CTA images of RICA. Despite the asymptomatic status, the multidisciplinary team members decided to qualify the patient for carotid artery angioplasty due to severe disease progression revealed in DUS. Coronarography revealed no coronary artery disease. Angiography confirmed significant RICA stenosis caused by FMD (Figure 2 C). With distal neuroprotection (FilterWire EZ, Boston Scientific, Natick, MA, USA), angioplasty with a $4.0 \times 20 \mathrm{~mm}$ balloon was performed (Figure $2 \mathrm{D}$ ). The immediate result was optimal, and no stent implantation was required (Figure $2 \mathrm{E}$ ). The periprocedural and postprocedural period was uneventful. For the next 36 months of follow-up the patient has remained neurologically asymptomatic with a preserved RICA angioplasty effect and stable LICA image in DUS.

Patient 3: A 51-year-old male patient with hypertension, chronic renal insufficiency and a history of left-side ischemic stroke 5 months earlier, after CAS performed due to string-sign (not typical for FMD) LICA stenosis 3 weeks earlier, was admitted for scheduled RICA-CAS. RICA 70\% stenosis was revealed during previous hospitalization, and it was confirmed in CT-angiography (Figures $3 \mathrm{~A}, \mathrm{~B}$ ). Figure $3 \mathrm{C}$ shows angiography of RICA performed directly before CAS. Long, irregular artery stenosis in its distal extracranial segment supported the diagnosis of FMD. With proximal neuroprotection (Mo.Ma 8F, Invatec, Roncadelle, Italy), angioplasty with a $4.0 \times 20 \mathrm{~mm}$ balloon (Figure $3 \mathrm{D}$ ), supported with self-expanding open-cell stent implantation (Precise $9.0 \times 40 \mathrm{~mm}$ ), was performed. The stent was postdilated with a $4.5 \times 20 \mathrm{~mm}$ balloon (Figure $3 \mathrm{E}$ ). The periprocedural and postprocedural period was uneventful, as was 14-month follow-up.

\section{Discussion}

The present study indicates that FMD is rare in patients with carotid artery stenosis scheduled for endovascular intervention, in our series $0.4 \%$. This proportion is lower than that reported by de Monyé et al. (0.5\%), who used computed tomography (CT) angiography as a screening tool [9]. It must be noted, however, that, in contrast to our group, they examined only neurologically symptomatic patients. The results of epidemiological studies indicate that multiple FMD lesions may be observed in the same patient including not only carotid and renal arteries but also intracranial circulation. The presence of intracranial aneurysms was reported by Stanley in $41 \%$ of patients with internal carotid artery FMD [10]. Similar results were reported by Frens, who confirmed intracranial aneurysms in $21 \%$ of patients referred for angiography due to cervical arterial FMD [11]. The prevalence of intracranial aneurysm in our group was $14 \%$ (1 out of 7). Endovascular FMD treatment requires administration of antiplatelet drugs including aspirin, clopidogrel and heparin periprocedurally. Thus, it is of key importance to perform angiography of both extracranial and intracranial arteries to evaluate the risk of endovascular intervention including the risk of periprocedural intracranial bleeding, which is significantly higher in patients with intracranial aneurysm. If there is a satisfactory balloon angioplasty effect, when stent implantation may be discarded, clopidogrel continuation is not necessary, and thus the risk of bleeding complications may be limited. Considering the high degree of coexistence of intracranial aneurysm and FMD, some advocate performing magnetic resonance imaging (MRI) of the cerebral circulation in every patient with FMD [12]. Although coronary angiograms in all patients did not reveal any abnormalities, patient no. 2 had a history of myocardial infarction confirmed by echocardiography on admission. This may support the observation of Saw et al., who found FMD in $86 \%$ of cases among spontaneous coronary artery dissection patients presenting with myocardial infarction [13]. It was also reported that most patients with FMD and MI have left anterior descending artery (LAD) involved [14]. 

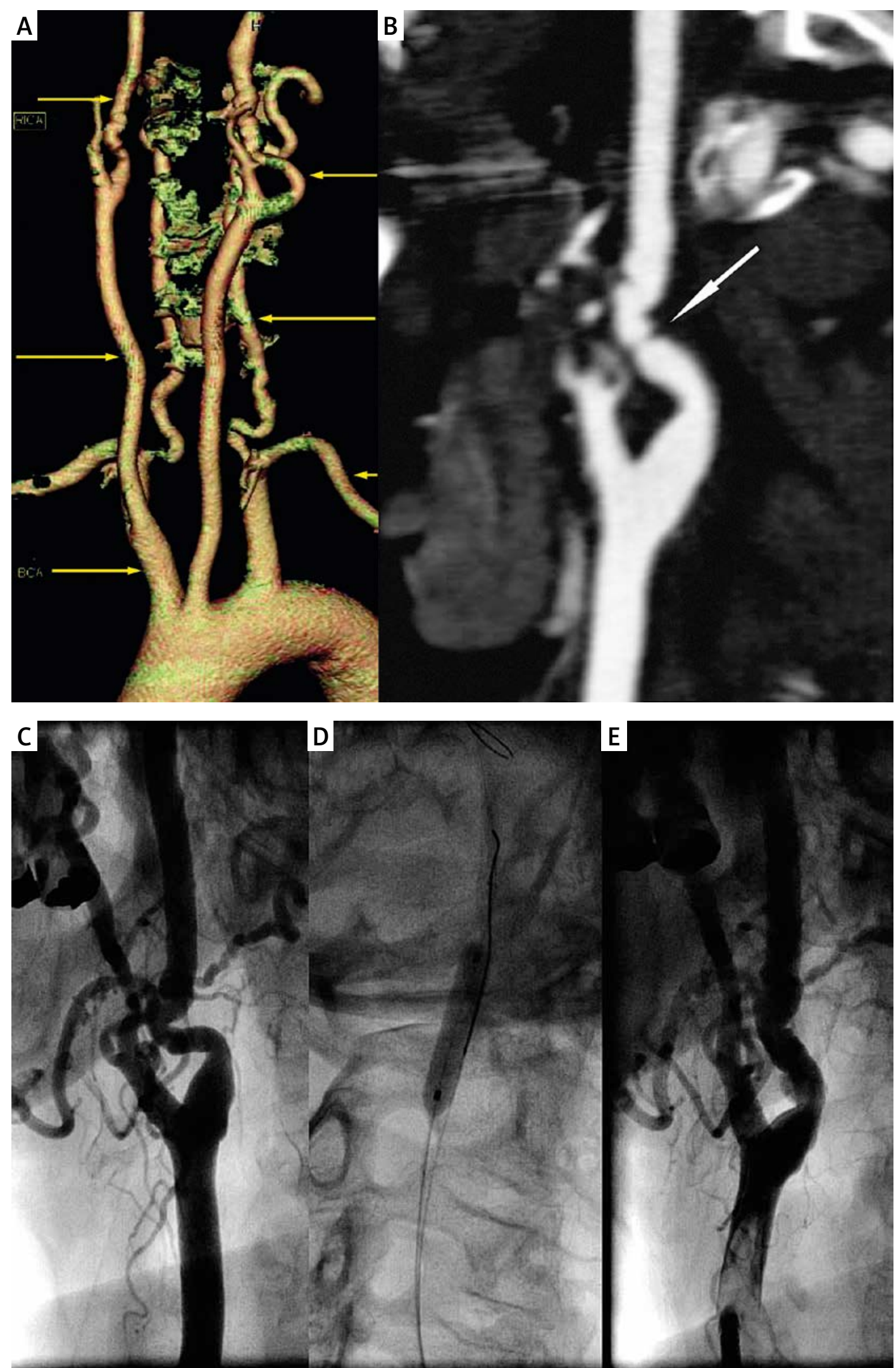

Figure 2. A 63-year-old female patient with hypertension and history of ST elevation anterior myocardial infarction presented with bilateral, asymptomatic ICA stenosis. A, B - CT angiography. A - 3D aortic arch reconstruction. B - vertical section of proximal RICA showing focal critical artery narrowing (arrow). C, D, E - catheter angiography. C - significant RICA stenosis caused by FMD. D - angioplasty with $4.0 \times 20 \mathrm{~mm}$ balloon with a distal neuroprotection system. $\mathrm{E}$ - optimal immediate result of balloon angioplasty, no need for stent implantation 

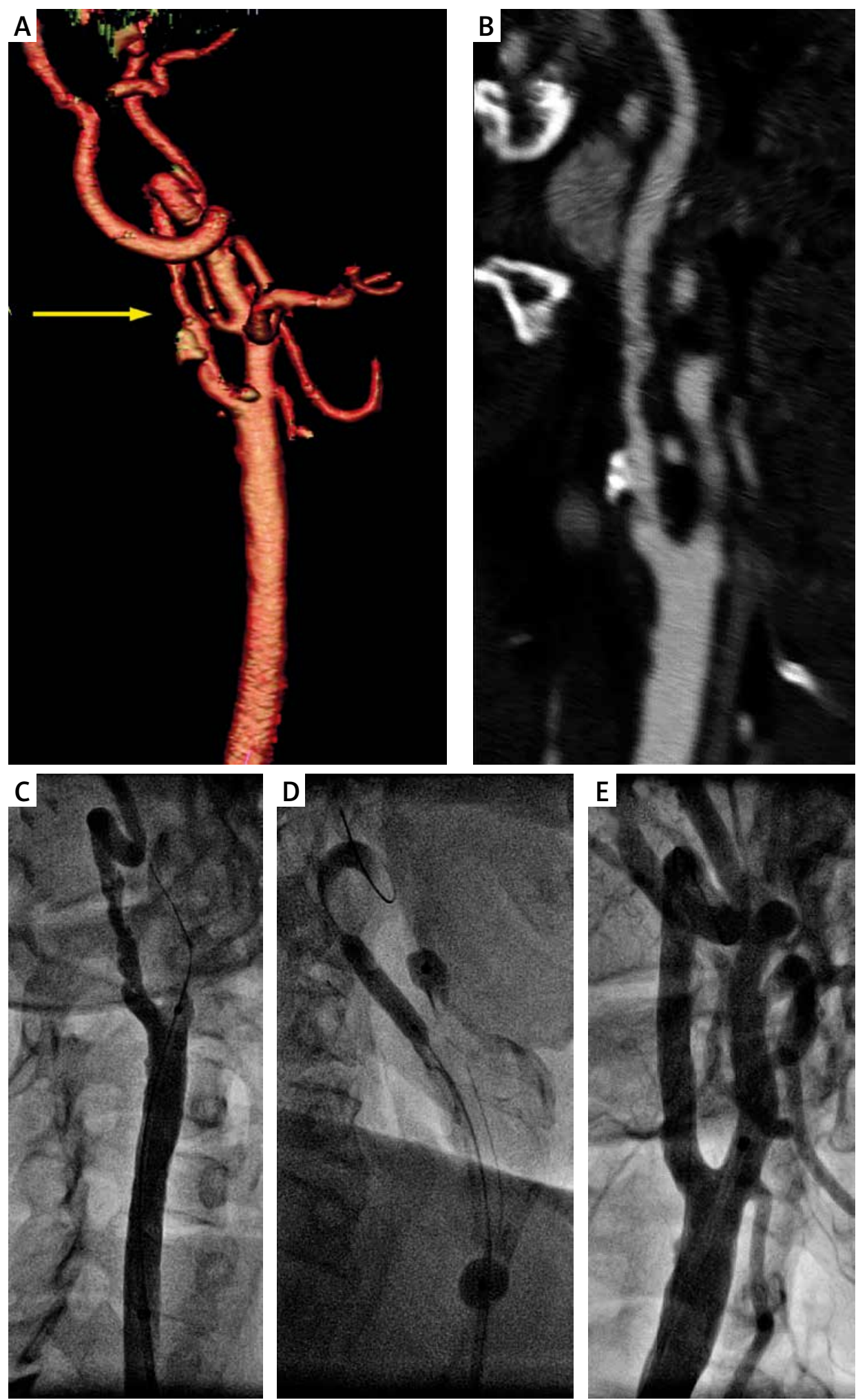

Figure 3. A 51-year-old male patient presented with hypertension, chronic renal insufficiency and history of ischemic stroke 5 months earlier, after CAS performed due to string-sign (not typical for FMD) LICA stenosis 3 weeks earlier admitted for scheduled RICA-CAS. A, B - 3D and 2D reconstructions in CT angiography showing long, irregular significant RICA stenosis. C, D, E - catheter angiography. C - significant RICA stenosis in its distal extracranial segment. D - proximal neuroprotected (Mo.Ma $8 \mathrm{Fr}$ ) angioplasty with $4.0 \times 20 \mathrm{~mm}$ balloon, supported with self-expanding open-cell stent implantation (Precise $9.0 \times 40 \mathrm{~mm}$, postdilated with $4.5 \times 20 \mathrm{~mm}$ balloon). E - optimal RICA-CAS result 
The apical aneurysm in echocardiography in our patient suggests the same pattern of coronary FMD.

For FMD detection DUS seems to be the best screening tool as non-invasive, safe and easily accessible. However, the ultrasonographer should keep in mind that typically FMD lesions, as opposed to atherosclerotic ones, are located at the level of the C1-C2 vertebra, and can be overlooked [15]. Thus, it is important to scan the carotid artery as distally as possible, and in case of doubt, further non-invasive evaluation should be considered. Both CT and MRI angiography have very good accuracy for detection of stenotic segments as well as other vascular pathologies accompanying FMD [16].

The endovascular treatment of symptomatic carotid stenosis provoked by FMD has been reported to be an effective and safe procedure [17]. It is unknown whether patients with symptomatic FMD are at higher risk of periprocedural complications as it may be observed in CAS for atherosclerotic origin stenosis $[6,18]$.

All patients described in this work had an uneventful periprocedural and postprocedural course, and good patency of angioplasty was established in > 24-month follow-up.

\section{Conclusions}

Fibromuscular dysplasia is rare among patients referred for carotid artery angioplasty. In the case of significant FMD stenosis, it may be treated with carotid angioplasty (stent supported if necessary) with optimal immediate and long-term results.

\section{Conflict of interest}

The authors declare no conflict of interest.

\section{References}

1. Schievink WI, Björnsson J. Fibromuscular dysplasia of the internal carotid artery: a clinicopathological study. Clin Neuropathol 1996; 15: 2-6.

2. Olin JW, Froehlich J, Gu X, et al. The United States Registry for Fibromuscular Dysplasia: results in the first 447 patients. Circulation 2012; 26: 3182-90.

3. Osborn AG, Anderson RE. Angiographic spectrum of cervical and intracranial fibromuscular dysplasia. Stroke 1977; 8: 617-26.

4. Collins GJ, Rich NM, Clagett GP, et al. Fibromuscular dysplasia of the internal carotid arteries. Clinical experience and follow-up. Ann Surg 1981; 94: 89-96.

5. Pieniążek P, Musiałek P, Kabłak-Ziembicka A, et al. Carotid artery stenting with patient- and lesion-tailored selection of the neuroprotection system and stent type: early and 5-year results from a prospective academic registry of 535 consecutive procedures (TARGET-CAS). J Endovasc Ther 2008; 15: 249-262.

6. Pieniążek P, Tekieli $九$, Musiałek $P$, et al. Carotid artery stenting according to the tailored-CAS algorithm is associated with a low complication rate at 30 days: data from the TARGET-CAS study. Kardiol Pol 2012; 70: 378-86.

7. Arning C, Grzyska U. Color Doppler imaging of cervicocephalic fibromuscular dysplasia. Cardiovasc Ultrasound 2004; 2: 7.
8. ASA/ACCF/AHA/AANN/AANS/ACR/ASNR/CNS/SAIP/SCAI/SIR/ SNIS/SVM/SVS Guideline on the management of patients with extracranialcarotid and vertebral artery disease. J Am Coll Cardiol 2011; 57: 1002-44.

9. de Monyé C, Dippel W. MDCT Detection of fibromuscular dysplasia of the internal carotid artery. Am J Roentgen 2007; 188: W367-9.

10. Ehrenfeld WK, Wylie EJ. Fibromuscular dysplasia of the internal carotid artery. Arch Surg 1974; 109: 676-81.

11. Frens DB, Petajan JH, Anderson R, Deblanc HJ Jr. Fibromuscular dysplasia of the posterior cerebral artery: report of a case and review of the literature. Stroke 1974; 5: 161-6.

12. Begelman SM, Olin JW. Fibromuscular dysplasia. Curr Opin Rheumatol 2000; 12: 41-7.

13. Saw J, Ricci D, Starovoytov A, et al. Spontaneous coronary artery dissection: prevalence of predisposing conditions including fibromuscular dysplasia in a tertiary center cohort. JACC Cardiovasc Interv 2013; 6: 44-52.

14. Huizar JF, Awasthi A, Kozman H. Fibromuscular dysplasia and acute myocardial infarction: evidence for a unique clinical and angiographic pattern. J Inv Cardiol 2006; 18: E99-101.

15. Boespflug OJM. Ultrasonography of supra-aortic trunks. Neuroradiology 1985; 27: 544-7.

16. Heiserman JE, Drayer BP, Fram EK, Keller PJ. MR angiography of cervical fibromuscular dysplasia. Am J Neuroradiol 1992; 13: 1454-7.

17. Olin JW, Sealove BA. Diagnosis, management, and future developments of fibromuscular dysplasia. J Vasc Surg 2011; 5: 826-36.

18. Kosowski M, Zimoch W, Gwizdek T, et al. Safety and efficacy assessment of carotid artery stenting in a high-risk population in a single-centre registry. Postep Kardiol Inter 2014; 10: 258-63. 